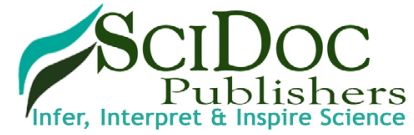

\title{
Water Activity Influence on Walnuts (Juglans Regia L.) Microbiological and Oxidative Stability
}

Research Article

Boaghi E*, Reşitca V, Ciumac J

Faculty of Food Technology, Food and Nutrition Department, Technical University of Moldova, Chisinau, Republic of Moldova.

\section{Abstract}

Walnut is the gold reserve of Republic of Moldova, being highly valued for their quality (size and protein content). In 2017, Republic of Moldova managed to become one of the top producers and exporters of walnuts in the world. Lipid oxidation and microbiological growth has been correlated to water activity, therefore the objective of this study was to identify the influence of water activity on walnut (Juglans Regia L.) oxidative and microbiological stability. Walnuts were stored under different water activities and maintained for 16 weeks. Through this period, changes of moisture, peroxide value and microorganisms' development were monitored. The highest oxidation rates were observed in walnuts stored under water activities ranges $0.0-0.28$ and $0.48-1.00$. Moisture content showed an increasing trend for all the water activity conditions.

Analyzing the obtained results, we concluded that to reduce the number of bacteria and molds, as well as peroxide value and moisture content from walnut kernel, with a view to preserve their quality, it is necessary that the water activity of storage rooms to fit in limits from 0.28 to 0.48 .

Keywords: Walnuts; Storage; Water Activity; Peroxide Value.

Abbreviations: AOCS: American Oil Chemists' Society.

\section{Introduction}

According to the International Trade Centre in Geneva, Moldova is one of the largest exporters of walnuts to Europe, after USA, Mexico and China [1]. Walnuts are grown on 11,000 hectares, an area that has been consistently expanding. This crop has rapidly grown during the last decade. Walnuts have generated considerable interest in the last decade because of their unique organoleptic characteristics $[2,3]$, high levels of polyunsaturated fatty acids $[4,5]$ and effects against cardiovascular diseases $[6-8]$. The beneficial effects are due to the fatty acid profile found in walnut oil, in particular the presence of $\omega-3$ and $\omega-6$ PUFA that are essential dietary fatty acids and have a favorable ratio in walnut oil $[9,10]$. Considering all these, high quality will increase competitive advantages and increase profits.
On the other hand, although the PUFA are essential for humans, they are susceptible to lipid oxidation [11,12]. During processing, walnut kernel, being highly hygroscopic is susceptible to microbial deterioration and spoilage when not properly stored. In the presence of oxygen, light, moisture, and high temperatures, oxidation of fatty acids can occur [13] and has been found to be a major source of off-flavors and decreased quality in walnuts $[14$, 15]. Walnut processors have reported shelf lives as short as one year due to oxidative rancidity $[16,17]$. Walnut storage conditions have significant effects on overall quality. Water activity plays an important role in walnut lipid oxidation. Control of water activity decreases oxidative rancidity in stored walnuts $[18,19]$. The aim of the present work was to highlight the effect of environmental water activity and storage time on the moisture content, oxidative stability and microorganisms' growth in walnut fruits.

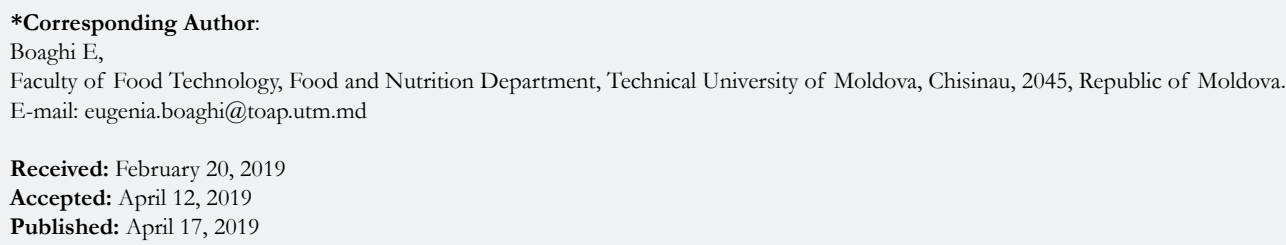

Citation: Boaghi E, Resitca V, Ciumac J. Water Activity Influence on Walnuts (Juglans Regia L.) Microbiological and Oxidative Stability. Int J Food Sci Nutr Diet. $2019 ; 8(2): 401-404$. doi: http://dx.doi.org/10.19070/2326-3350-1900071

Copyright: Boaghi $\mathbf{E}^{\mathcal{O}}$ 2019. This is an open-access article distributed under the terms of the Creative Commons Attribution License, which permits unrestricted use, distribution and reproduction in any medium, provided the original author and source are credited. 


\section{Materials and Methods}

\section{Materials}

In order to perform research there were used qualitative walnuts collected in 2015 that correspond to the UNECE STANDARD DDP-02 demands.

\section{Methods}

Sample Preparation and Storage: In order to create different storage conditions, with different water activities, triplicate samples of walnuts were stored in glass desiccators containing solution of $\mathrm{H}_{2} \mathrm{SO}_{4}$ with concentration range: from $0 \%-60 \%$. The samples were maintained in desiccators during 16 weeks.

Lipid Extraction and Peroxide Value Determinations: Walnut oil was extracted from the walnuts using a laboratory press. The Official American Oil Chemists' Society [AOCS] method was used to measure peroxide values and results reported as milliequivalents peroxide/ $\mathrm{kg}$ oil (AOCS Cd 8-53).

Moisture Determination: The moisture evolution of stored walnuts was determined, in triplicate, using the AOAC - Official Method 925.40 (moisture in nuts and nut products).

Microbiological Analysis: The microbiological tests concerning the microorganism count (molds and bacteria) were done every two weeks for each walnut sample. For the isolation of foodborne pathogens, aliquots of samples were placed on Nutrient Agar and Sabouraud medium. Cultures were incubated in Petri dishes under appropriate rules on culture media indicated $\mathrm{pH}$ of 2.5 to 5.5 which were kept in thermostat for $48-72$ hours at $\mathrm{t}=32-37^{\circ} \mathrm{C}$. The colonies observed were counted and sub-cultured for identification.

Experimental Design: One glass desiccator was assigned to a certain environmental water activity. An aliquot of walnuts (500 g) was placed in each of the desiccators. All desiccators were stored at $20^{\circ} \mathrm{C}$ for 16 weeks. Every 2 weeks, a sample of $60 \mathrm{~g}$ was collected from each container to analyze the evolution of moisture content, peroxide value and microorganisms' growth.

\section{Results and Discussions}

\section{Moisture Evolution}

The walnut moisture content increased under all storage conditions (Figure 1) and ranged between $0.243( \pm 0.004)-0.874$ $( \pm 0.006) \mathrm{g} \mathrm{H}_{2} \mathrm{O} / \mathrm{g}$ product. The moisture was still increasing for all samples even at 16 week - storage. Even at the lowest water activities $\left(\mathrm{a}_{\mathrm{w}}=0.015\right)$, moisture increased from about 7\% (the initial moisture level) to almost $24 \%$ by week 16 . The obtained results show that walnuts are clearly hygroscopic, and readily pick up moisture even at extremely low water activities, and this can be explained by the chemical composition of walnuts morphological parts (shell and inner membrane) that are rich in lignins and therefore can absorb water.

\section{Evolution of Peroxide Values (PVs)}

As mentioned above, the major component of walnuts are fats. They are relatively unstable, easily oxidized and give walnuts a bitter taste. The degree of oxidation of walnut fats depends largely on their storage conditions and the value of their water activity. The evolution of the peroxide value of walnut fats depending on water activity during the storage of walnuts within 16 weeks is presented in the table below.

The results show that the processes of oxidation of walnut fats according to the water activity have a parabolic character (Figure 2 ), the minimum value being recorded at water activities of 0.28 ... 0.48. The initial value of the peroxide value was relatively low $(0.60 \pm 0.04 \mathrm{meq} / \mathrm{kg})$. During storage, PV values increased continuously, but the rate of growth depended largely on the water activity in the storage medium, being lower at intermediate values aw $\approx 0.30-0.50$. Labuza (1975) and others have reported similar results $[20,21]$. Final PV values were significantly affected by water activity and constituted $2.90-5.60 \mathrm{meq} / \mathrm{kg}$, the minimum value being set at $\mathrm{a}_{\mathrm{w}}=0.48$.

Oscillations of water activity in storage areas result in adsorption or desorption of water and change in moisture of walnuts. The results show that in the degradative processes (oxidation) of lipids, water plays both protective roles and prooxidative roles. Analyzing the data presented in Table 1 and Figure 2, we can dis-

Figure 1. Evolution of moisture content of walnuts during storage at different water activities.

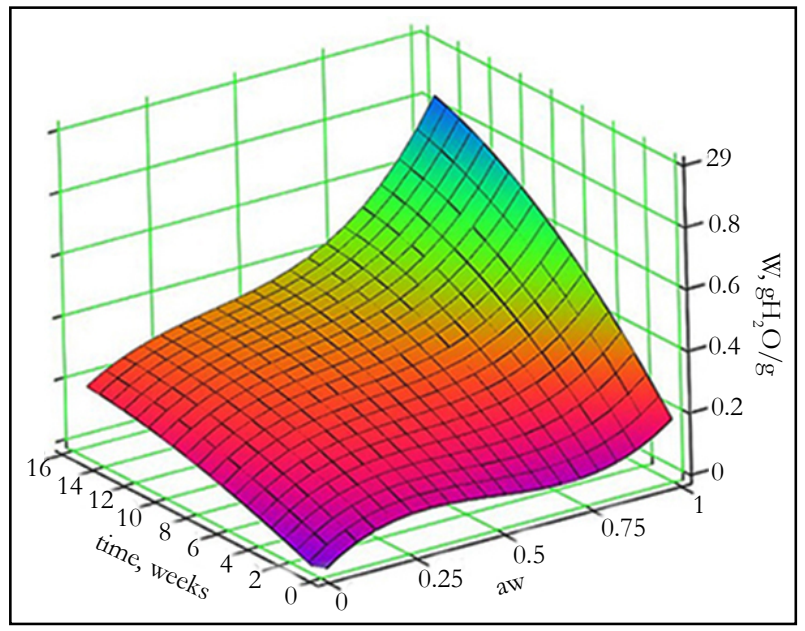


Table 1. Peroxide value evolution (PV*, meq/kg) of walnut lipids depending on water activity and storage period.

\begin{tabular}{|c|c|c|c|c|c|c|c|c|c|c|c|}
\hline $\mathbf{a}_{\mathbf{w}}$ & $\mathbf{0 . 0 8}$ & $\mathbf{0 . 1 5}$ & $\mathbf{0 . 2 3}$ & $\mathbf{0 . 2 8}$ & $\mathbf{0 . 4 8}$ & $\mathbf{0 . 5 2}$ & $\mathbf{0 . 6 1}$ & $\mathbf{0 . 7 1}$ & $\mathbf{0 . 8 1}$ & $\mathbf{0 . 9 2}$ & $\mathbf{1 . 0 0}$ \\
\cline { 1 - 9 }$\tilde{\mathbf{i}, \text { week }}$ & & & & & & & & & & & \\
\hline 0 & 0.60 & 0.60 & 0.60 & 0.60 & 0.60 & 0.60 & 0.60 & 0.60 & 0.60 & 0.60 & 0.60 \\
\hline 2 & 0.60 & 0.60 & 0.60 & 0.60 & 0.60 & 0.60 & 0.60 & 0.60 & 0.60 & 0.60 & 0.60 \\
\hline 4 & 1.40 & 1.10 & 0.90 & 0.75 & 0.75 & 0.90 & 0.99 & 1.10 & 1.16 & 1.20 & 1.30 \\
\hline 6 & 1.98 & 1.60 & 1.30 & 1.10 & 0.90 & 1.10 & 1.18 & 1.21 & 1.38 & 1.50 & 1.65 \\
\hline 8 & 2.60 & 2.10 & 1.70 & 1.30 & 1.15 & 1.38 & 1.56 & 1.78 & 1.92 & 2.25 & 2.39 \\
\hline 10 & 3.30 & 2.86 & 2.30 & 1.70 & 1.40 & 1.62 & 1.99 & 2.20 & 2.60 & 2.78 & 3.08 \\
\hline 12 & 4.10 & 3.52 & 2.93 & 2.30 & 1.82 & 1.95 & 2.25 & 2.61 & 3.15 & 3.68 & 3.88 \\
\hline 14 & 4.80 & 4.05 & 3.35 & 2.45 & 2.15 & 2.26 & 2.62 & 3.18 & 3.92 & 4.31 & 4.60 \\
\hline 16 & 5.60 & 4.90 & 4.22 & 3.40 & 2.90 & 3.16 & 3.57 & 3.99 & 4.53 & 5.06 & 5.38 \\
\hline
\end{tabular}

$* \mathrm{PV}=\mathrm{PV} \pm 0.04$

Figure 2. Colony forming units of (a) yeasts and molds and (b) bacteria in walnuts depending on the water activity in the storage areas.
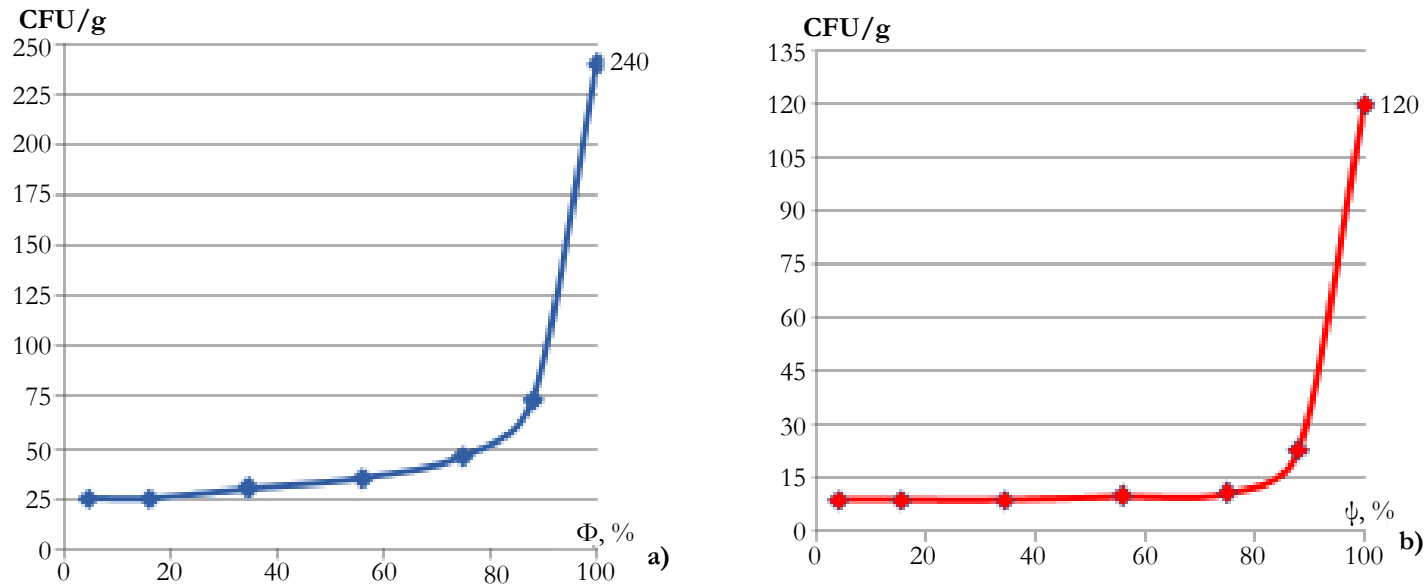

tinguish three phases of the lipid oxidation process in walnuts.

In the first phase, when water activity has low values $(0.01-0.27)$, water exerts an antioxidant effect explained by the formation of hydrogen bonds between water molecules and hydroperoxide molecules. These complexes protect the hydroperoxides from decomposing into free radicals, so that the reaction rate is relatively low.

The second phase takes place at an intermediate value of the water activity $(0.28-0.48)$ in which the rate of oxidation reaction increases. In the storage of walnuts at intermediate values of the water activity, part of the contained water is located in the monolayer at the outer surface of the pores, and another part covers the surface of the ionic and polar groups of the lipids, thus preventing their direct exposure to air. The mobility of monolayer water molecules is very limited, which is why it cannot serve as a reaction medium and does not participate in chemical reactions.

The third phase takes place at high water activity values between 0.48 and 1.00. Excess moisture increases the enzymatic activity of walnuts and facilitates the degradation of oils by lipase, which produces free fatty acids and by lipoxygenase oxidizing the polyunsaturated compounds resulting in the appearance of rancid taste and some unpleasant flavors and odors.

Thus, at water activities of $0.08-0.28$ and $0.48-1.00$ the oxidation processes know a maximum intensity, water molecules form multiple layers around the product, or are generally lacking, thus opening oxygen access to the lipid substrate.

In the range of water activities of 0.28 - 0.48 oxidation processes are characterized as slow, only one layer of water molecules is formed around the product, so it cannot exhibit its solvent properties for conducting chemical reactions, as well it acts as a barrier to oxygen access.

\section{Microbiological analysis}

Another important aspect, depending on the water activity of the walnut storage areas, is their contamination with molds [22]. The value of the microbiological load was determined depending on the water activity in the walnut storage facilities. The results obtained are shown in Figure $2 \mathrm{a}$ and $\mathrm{b}$.

To assess the total number of colonies of bacteria, the Nutritive Agar medium was used, the results show that their number increases slightly with increasing water activity to 0.9 and much faster at higher values, and for the evaluation of the total number of yeasts and mold the environment was used Sabouraud. 
The identification of microorganisms was based on the analysis of phenotypic characteristics corresponding to cultural characters and morphological characters. Cultural characteristics are taxonomic criteria that characterize morphological expression, the way of development of microorganisms and the appearance of microbial masses: the time of appearance of the colonies, the uniformity, the shape (circular, irregular, corrugated, etc.), the profile, the color, the consistency, the size, etc.

It has been found out that intensive proliferation of yeasts and molds on the walnut surface begins at lower water activity levels, i.e. they are more xerophilic than bacteria. Among the present molds there were Aspergillus niger, Aspergillus flavus, Fusarium, while the identified bacteria were Bacillus subtilis, Pseudomonas and Staphylococcus. Some groups of these fungi have been reported by Riyaz-Ul-Hassan (2003) as the most predominantly encountered species of fungi from deteriorating walnuts. The interacting effect of water activity on the growth of the fungi shows that $0.15-0.34$ water activity was the best storage condition as some fungi were eliminated.

\section{Conclusion}

Walnut storage conditions have significant effects on overall quality, especially if the product is to maintain high quality over long periods of storage. Containing more than $90 \%$ unsaturated fatty acids, walnuts maintain best product quality (low oxidation rate, maintenance of desirable flavor and taste) when stored at water activities between 0.28 and 0.48 . Above this range oxidation and microorganisms growth increased, whereas below the range, the oxidation rate increased.

\section{References}

[1]. McNeil DL. A global perspective of walnut production. Acta Hortic. 2009 Feb;861:25-30.

[2]. Downs ML, Simpson A, Custovic A, Semic-Jusufagic A, Bartra J, FernandezRivas $\mathrm{M}$, et al. Insoluble and soluble roasted walnut proteins retain antibody reactivity. Food Chem. 2016 Mar 1;194:1013-21. doi: 10.1016/j.foodchem.2015.08.119. PubMed PMID: 26471647.

[3]. Iqbal M, Bhatti IA, Shahid M, Nisar J. Physicochemical characterization, microbial decontamination and shelf life analysis of walnut (Juglans regia $\mathrm{L}$ ) oil extracted from gamma radiation treated seeds. Biocatal Agric Biotechnol. 2016 Apr 1;6:116-22.

[4]. Bujdoso G, Konya E, Berki M, Nagy-Gasztonyi M, Bartha-Szuegyi K, Marton B, et al. Fatty acid composition, oxidative stability, and antioxidant properties of some Hungarian and other Persian walnut cultivars. Turkish Journal of Agriculture and Forestry. 2016 Feb 5;40(2):160-8.

[5]. Copolovici D, Bungau S, Boscencu R, Tit DM, Copolovici LU. The fatty acids composition and antioxidant activity of walnut cold press oil. Revista De Chimie. 2017 Mar 1;68(3):507-9.

[6]. Abe LT, Lajolo FM, Genovese MI. Comparison of phenol content and antioxidant capacity of nuts. Food Sci Technol Res. 2010 May;30:254-9.

[7]. Sánchez-González C, Ciudad CJ, Noe V, Izquierdo-Pulido M. Health benefits of walnut polyphenols: An exploration beyond their lipid profile. Crit Rev Food Sci Nutr. 2017 Nov 2;57(16):3373-3383. doi: 10.1080/10408398.2015.1126218. PubMed PMID: 26713565.

[8]. Njike VY, Ayettey R, Petraro P, Treu JA, Katz DL. Walnut ingestion in adults at risk for diabetes: effects on body composition, diet quality, and cardiac risk measures. BMJ Open Diabetes Res Care. 2015 Oct 19;3(1):e000115. doi: 10.1136/bmjdrc-2015-000115. PubMed PMID: 26688734.

[9]. Amaral JS, Casal S, Pereira JA, Seabra RM, Oliveira BP. Determination of sterol and fatty acid compositions, oxidative stability, and nutritional value of six walnut (Juglans regia L.) cultivars grown in Portugal. J Agric Food Chem. 2003 Dec 17;51(26):7698-702. PubMed PMID: 14664531.

[10]. Fink A, Rüfer CE, Le Grandois J, Roth A, Aoude-Werner D, Marchioni E, et al. Dietary walnut oil modulates liver steatosis in the obese Zucker rat. Eur J Nutr. 2014;53(2):645-60. doi: 10.1007/s00394-013-0573-z. PubMed PMID: 23942585.

[11]. Martinez ML, Curti MI, Roccia P, Llabot JM, Penci MC, Bodoira RM, et al. Oxidative stability of walnut (Juglans regia L.) and chia (Salvia hispanica L.) oils microencapsulated by spray drying. Powder Technol. 2015 Jan 1;270:271-7.

[12]. Xie C, Ma ZF, Li F, Zhang H, Kong L, Yang Z, et al. Storage quality of walnut oil containing lycopene during accelerated oxidation. J Food Sci Technol. 2018 Apr;55(4):1387-1395. doi: 10.1007/s13197-018-3053-x. PubMed PMID: 29606753.

[13]. Fu M, Qu Q, Yang X, Zhang X. Effect of intermittent oven drying on lipid oxidation, fatty acids composition and antioxidant activities of walnut. LWT - Food Sci Technol. 2016 Jan 1;65:1126-32.

[14]. Gama T, Wallace HM, Trueman SJ, Hosseini-Bai S. Quality and shelf life of tree nuts: a review. Scientia horticulturae. 2018 Dec 19;242:116-26.

[15]. Qu Q, Yang X, Fu M, Chen Q, Zhang X, He Z, et al. Effects of three conventional drying methods on the lipid oxidation, fatty acids composition, and antioxidant activities of walnut (Juglans regia L.). Drying Technol. 2016 May 18;34(7):822-9.

[16]. Hosseini H, Ghorbani M, Mahoonak A, Maghsoudlou Y. Monitoring hydroperoxides formation as a measure of predicting walnut oxidative stability. Acta Aliment. 2014 Aug 1;43(3):412-8.

[17]. McNeil DL, Felgate MK. Analysis of UK walnut market import purchase behaviour. Br Food J. 2014 Feb 25;116(3):405-18.

[18]. Marchetti L, Romero LM, Andres SC, Califano AN. Characterization of pecan nut expeller cake and effect of storage on its microbiological and oxidative quality.

[19]. Maté JI, Saltveit ME, Krochta JM. Peanut and walnut rancidity: effects of oxygen concentration and relative humidity. J Food Sci. 1996 Mar;61(2):4659.

[20]. Labuza TP. Interpretation of sorption data in relation to the state of constituent water. In: Water Relations of Foods. Duckworth RB. New York: Academic Press; 1975. p. 155-172.

[21]. Rabrenovic B, Dimic E, Maksimovic M, Sobajic S, Gajic-Krstajic L. Determination of fatty acid and tocopherol compositions and the oxidative stability of walnut (Juglans regia L.) cultivars grown in Serbia. Czech J Food Sci. 2011 Feb 14;29(1):74-8.

[22]. Riyaz-Ul-Hassan S, Verma V, Malik A, Qazi GN. Microbiological quality of walnut kernels and apple juice concentrate. World J Microbiol Biotechnol. 2003 Nov 1;19(8):845-50. 